a greater mass overhead, and conse yuently greater heat. In the case of the Gothard, an increase of depth of $44 \mathrm{~m}$. occasioned a rise in the temperature of $1^{\circ} \mathrm{C}$. On this hypothesis, which is of course rough and approximate, in the middle of the work the thermometer will read about $40^{\circ} \mathrm{C}$. In the Cenis the maximum temperature reached was $29^{\circ} \mathrm{C}$; ; but the workmen had to submit to this temperature for a short time only. In the Gothard the temperature of $3 \mathrm{I}^{\circ} \mathrm{C}$. had to be contended with for a long distance, and the sufferings were proportionately severe. Anæmia and kindred diseases played havoc with the workpeople. Some 60 per cent. of the workers, it is reckoned, were attacked ; and to prevent a similar disaster in the present undertaking, another set of problems, dealing with ventilation and sanitation, had to be considered as part of the entire mechanical difficulties that present themselves.

The lines along which the main engineering problem has been solved are tolerably well known. The scheme contemplates the construction of two parallel tunnels, whose axes will be separated liy 17 metres. These two parallel roads will be connected at regular intervals by transversal galleries leading from one to the other, capable of being closed at will by air-tight doors. Only one of the main tunnels will at present receive its final dimensions, and be fully finished for traffic. The breadth will be $5 \mathrm{~m}$., and the height above the sleepers $5.5 \mathrm{~m}$. These dimensions will permit only a single line of rails to be laid, and provision is made in the middle of the tunnel for a siding 400 $\mathrm{m}$. long, so that two trains may pass in opposite directions. The object of the second tunnel, which will have a section of eight square metres, is mainly to ensure sufficient ventilation, ind, indeed, to make the work in the main gallery possible. It was this ingenious thought, of carrying along simultaneously the two galleries, which has brought the perforation of the Simplon within the range of possibilities. This suggestion is due to Herr Brandt, of the firm with whom the contract has been placed. The distinguishing feature of this proposal is that it will ensure a current of air passing through the entire system of the tunnels. Evidently, if ventilating apparatus be placed at the entrance of either gallery, a current of air can be forced through one tunnel, through the transverse gallery at the end of the working (all the intermediate openings being closed), and out through the other tunnel. If it be objected that the construction of the second gallery is a very expensive method of supplying fresh air to the workpeople, the answer is that, without some such means, the perforation is found to be impracticable. But the expense is not so great as it seems, because the second gallery can at no very great additional cost be made available for traffic when this increases to such an extent as to make the single line first laid insufficient. It is proposed to supply through this supplementary tunnel $50 \mathrm{cb} . \mathrm{m}$. of air per second, by means of a current moving with the velocity of 13 miles an hour. Such a supply is far in advance of the quantity available at the Saint Gothard workings, and is to some extent founded on the amount that is found necessary to ventilate the Mersey tunnel. In this latter case the supply of fresh air, which no one who has made the journey from Birkenhead to Liverpool would say is excessive, is, it is true, four times greater than the quantity that will be pumped into the Simplon passage but the number of trains that pass in a day is considerably more, under the Mersey, than will be the case in the Simplon passage. Such a current may, therefore, be sufficient for the workmen, and will certainly tend to reduce the high temperature; but the engineers will not trust to this means alone, to make the interior of the cutting endurable. Recourse will be had to the distribution, throughout the workings, of fine water-dust under considerable pressure. If the water, as it is hoped, can be delivered at the rock face at a temperature of $12^{\circ}$ C., it can be employed with the happiest effect. Experiments made at Winterthur, before a committee of experts, proved that an air temperature of $40^{\circ}-50^{\circ} \mathrm{C}$. could be lowered to $15^{\circ}$ by employing a water-dust of $12^{\circ} \mathrm{C}$. under a pressure of five and a half atmospheres. When higher pressures are available a still more marked result is produced, and the abundant supply of water at both ends of the tunnel will permit this method to be tried under very favourable circumstances.

This large supply of water, from the Rhone on the north side, and from Italian streams on the south, very fortunately permits the use of hydraulic machinery as a means of economically. working the boring apparatus. In other works of similar character, compressed air has been the agent employed, against the use of which some objections have heen urged. We have here, therefore, the means of comparing the efficiency of the two methods, both in the operation of cutting through the hard gneiss rock, and the effect on the health of the operators, on whom the escape of the compressed air is said to work dis. advantageously. On the Arlberg, the natural surroundings of which are comparable with those to be met on the Simplon, the Brandt hydraulic perforating machine has given great satisfaction. It is contended by its supporters that, in a work of such magnitude, where the power has to be supplied from a great distance, that hydraulic transmission is to be preferred to all other, because with it the loss of force is the least. From actual experiment on gneiss rock, it has been shown that a perforation I $\mathrm{m}$. deep and $70 \mathrm{~mm}$. diameter can be bored in 12 to 25 minutes, and that consequently a daily advance of $5.85 \mathrm{~m}$. can be reckoned upon. That. M. Brandt has the greatest confidence in his invention and in his methods is shown by the fact that, in the contract which he has signed, he is willing to submit to a fine of 5000 francs a day in case the work is not completed in the five and a half years he allows himself. The total cost of the entire construction is computed at less than $3,000,000 /$. It is interesting to compare the rate of progress and cost of construction of the three tunnels which will compete for the TransAlpine traffic. In the case of the Mont Cenis tunnel, which represents the state of mechanical science some thirty years since, a year, approximately, was required to complete each kilometre at a cost of six millions of francs. The Saint Gothard, about ten years later in date, proceeded twice as rapidly, while the cost of construction dropped to four million francs per kilometre. Herr Brandt, however, proposes to complete four kilometres per annum, at the same time reducing the expense per kilometre to one half that of the earliest tunnel. One may well wish that this sanguine estimate will be justified.

\section{ON THE COLOUR AND COLOUR-PATTERNS OF MOTHS AND BUTTERFLIES.}

A PAPER by Mr. Alfred Goldsborough Mayer, on "The Colour and Colour-Patterns of Moths and Butterflies" (Proceedings of the Boston Society of Natural History, vol. xxvii. No. 14, pp. 243-330, March i897), is a rather elaborate discussion of a subject which has lately attracted much attention; but though Mr. Mayer has made some interesting experiments and observations, his results are neither so novel nor so important as he claims them to be. One of the most interesting parts of the paper is the account of the development of wingcolours during the pupal state, a summary being given of previous researches, supplemented by a series of new observations on common species of American moths and butterflies. The result arrived at is, that the wings are at first transparent, then white, then drab or dusky yellow, while all the purer and brighter colours arise later on. This is what might be expected from the general distribution of colour in lepidopterous insects, and has been indicated by Dr. Dixie and other writers as probable.

Some ingenious experiments were made for the purpose of ascertaining whether the wing-scales were of any use in giving a greater hold on the air. The wings, with and without scales, were attached to a delicate pendulum, but no measurable difference in air-friction was found. Neither do the scales perceptibly strengthen the wings, hence it was concluded that they have been developed solely as colour-producing organs of use to the various species.

A considerable space is devoted to the development of the colour-patterns of the Danaoid and Arcreoid Heliconidæe and the phenomena of mimicry. These are illustrated by four coloured plates intended to show the markings of a large number of species. These plates do not represent the insects themselves, but are "projected by Keeler's method" on rectangles of uniforn size, which are supposed to afford more accurate means of comparison. This will seem to most naturalists to be a great mistake. It not only renders the patterns of the most familiar species almost unrecognisable, but it introduces many possibilities of errur in the process of pr 3jection which even a comparison with the species represented may not enable us to detect. In the case of mimicking species it has the further disadvantage of obscuring differences of outline, and by irregular distortion giving undue prominence to what may be very slight differences in the actual species. In many mimicking species there is a wonderful similarity of

NO. [435, VOL. 55] 
general effect comhined with considerable differences of detail, and by the process of "projection" these differences of detail may be exaggerated while the general similarity is obscured.

While accepting Fritz Müller's explanation of the mimicry of protected species by each other, and as also affording the only intelligible reason for there being only two types of colourpattern in the whole 400 species of the Danaoid Heliconidre, he says that "unfortunately no direct experiments have been made on the feeding habits of young South American birds." But in view of the careful experiments of Prof. Lloyd Morgan on a variety of young birds this is hardly necessary, as it is proved that they have in no case any instinctive knowledge of what is edible or distasteful, while they acquire the knowledge by experience with extreme rapidity. Like many other writers on the subject who have recently criticised and rejected the theory of warning colours as indicating inedibility, Mr. Mayer does not distinguish between the habitual and the only occasional enemies of protected insects. Thus he refers to the experiments of Beddard, showing that toads will eat any insects whatever; but it is quite certain that toads are not very dangerous enemies to either butterflies or their larvæ, nor probably are marmosets which are also general feeders. There is quite sufficient evidence to show that insects with warning colours are rejected by most insectivorous birds and lizards, which are certainly the most general and most dangerous devourers of insects both in the larva and winged state, and these facts, taken in conjunction with the experiments of Prof. Lloyd Morgan, afford a firm foundation for the whole iheory of warning colours and mimicry.

A. R. W.

\section{THE PRIMATE BRAIN. ${ }^{1}$}

[HE comparative study of the convolutions of the brain surface in man, apes and monkeys, may be said to have been founded by Gratiolet, who mapped out the fissures in the lower monkeys, traced the patterns upwards through the apes to man, and invented a system of names for the convolutions. In recent years this study has received impulse from two distinct causes on the one hand, the greater opportunity of examining the brains of the higher apes; and, on the other, the attempt to locate in the convolutions definite functions has led to experiments being conducted, by physiologists and psychologists, upon the brains of monkeys. A great variation in the convolutions of species of monkeys and of apes has been thereby shown to exist, and more accurate data have been rendered available for a true morphological comparison with those of man; and although the subject has, to a very great extent, been attacked from a physiological standpoint, yet the morphology of the convolutions has received increased attention during the past few years, notably at the hands of Dr. Cunningham, whose careful and extended work on this subject covers a good deal of the ground opened up in the present memoir, which deserves a place alongside that of the Dublin anatomist.

The publication of Dr. Parker's work, which was communicated verbally, to the Academy of Philadelphia, as long ago as I 890 , has been delayed till last year, owing to a variety of circumstances-amongst others, the death of the author in 1892. After an introduction dealing with the scope and aim of the memoir, there follows an interesting historical survey of the observations and opinions of the chief writers on the subject. The anthor then tabulates the names of the fissures and convolutions applied to the human brain, with their synonyms as employed by each author. This table will be of considerable value to students of the subject, as will be the historical survey.

How are these convolutions and furrows on the surface of the brain brought about? What is the cause of the gyrencephalous condition? This is still a matter of controversy. To this question two chief, but opposing answers have been suggested, each supported by equally competent authorities. The one school looks on these convolutions as due to the effect of pressure of the slowly growing skull on the more rapidly growing brain. The opposite school believe the cause to be innate-that is to say, the convolutions owe their origin to differential growth in certain definite regions of the brain surface itself. Dr. Parker combines these two opposing views : believing that certain "fundamental

x "Morphology of the Cerebral Convolutions, with special reference to the Order of Primates." By Andrew J. Parker, M,D. Journ. Acad. Nat. Sci. Philadelphia, and series, vol. x, 1896, pp. 247 to 362 ; with fifteen plates and several figures in the text. fissures" are produced by mechanical causes, whilst others owe their origin to morphological processes of growth in the bram substance; the fissures, of course, representing lines of retarded growth. During early development, it is the brain which modifies the shape and structure of the skull, rather than the reverse; ultimately, as the skull grows more rigid, its influence is shown in the increasing tortuosities of the folds.

The development of the human brain is traced out, so far as is necessary to explain the author's views, and the various stages are compared with the adult brain of monkeys. At the age of three months the foetal human brain consists of three lobes, which he terms the "occipito-frontal," "occipito-temporal," and "occipital." It does not immediately appear evident why the author eniploys compound names for the two former lobes, unless it be to insist as strongly as possible upon the fact that there is no such thing as "parietal lobe," at any rate as a morphological equivalent of the others. The "island of Reil" is not homologous with a "lobe," but is developed at the bottom of a depressed area, the fossa sylviz. Each of the three lobes contains a portion of the lateral ventricle; each will exhibit a similar, and iymmetrical series of furrows. He points out here, as elsewhere, that the "occipital" lobe, developed as it is round the posterior cornu of the lateral ventricle, is peculiar to the Primates.

During the third month a certain number of "temporary furrows" make their appearance on the surface of the hemispheres ; they radiate from the region of the sylvian fossa, and when viewed from the mesial surface, lines drawn through all but those in the occipital lobe meet at a centre which lies in the cerebral peduncle: and the angle included between any two neighbouring lines is constantly $60^{\circ}$, or thereabouts. This fact he makes use of in considering the callses concerned with the production of these fissures, which he attributes to pressure between brain and skull.

But, as is well known, these temporary fissures disappear, and the brain again becomes smooth for a short time at about the fifth month; and he lays great stress on this smooth brain, with its three lobes, a sylvian fissure, a calcarine fissure, and "mesial arched fissure." The author regards this stage as the fundamental plan of the Primate brain ; indeed, this is essentially the marmoset's brain enlarged. Later on, new fissures appear, and he recognises, in addition to the (1) fundamental or primary fissures, just mentioned, the (2) secondary fissures, (3) sulci of Pansch, mere vegetative repetitions of $(2) ;(4)$ sulculi, which are inconstant, and (5) rami, which are the branches of $(2)$ or (3). The mesial arched fissure gives rise to the callosal and the hippocampal fissures ; each of which, with the calcarine, is similarly related to one of the three primary lobes.

The occipital lobe next becomes definitely marked off from the rest by two fissures, a dorsal and a ventral, constituting the "primary occipital arch." The dorsal one is the "parietooccipital" or "perpendicular fissure" of monkeys. The mesial ends of these are symmetrical with regard to the calcarine. These fissures, again, are regarded as being due to pressure.

This stage represents the characteristic Simian brain (including that of man).

Parker disagrees with the usual view, that the fissure of Folando is a primary fissure; nevertheless, it is certainly characteristic of the primate brain, for it occurs in no other order. He explains the fissure in an ingenious manner, by reference to a lemur's brain, in which there are two longitudinal fissures extending along the fronto-occipital lobe; a part of the upper one is supposed to become vertical. But no ontogenetic evidence is forthcoming for this view, which would lead us back readily to the condition of a carnivore's brain.

It is impossible to give briefly his many interesting suggestions as to the homologues of the frontal and parietal convolutions; but special interest will be taken in his account of the occipital convolutions, for these have always troubled anatomists, who have until recently regarded them as being more or less irregularly arranged, and consequently have neglected them. Parker endeavours to show that they can be reduced to order, especially if the development of the "plis de passage" or "annectant gyri" be taken into account. These rise up, as I have shown in discussing the brain of the chimpanzee "Sally," and as others have also shown, from the bottom of fissures; so that in one brain they may be hidden, in another they come to the surface and divide single fissures into two. Parker says: "The typical fissures represent the lines of least resistance to the differential action of the pressure forces.

NO. [435, VOL. 55] 